\title{
Analysis on Clothing Consumption Differences between Urban and Rural Residents in China
}

\author{
Jianghong $^{1}$; Zhaohong ${ }^{2}$ \\ College of Economics, Tianjin Polytechnic University,Tianjin,China,300387 \\ aemail,
}

Key words:Clothing; Consumption; Urban and Rural Residents; Difference

\begin{abstract}
At present, China is not just a textile and clothing exporting country, with the development of china's domestic economy, urbanization reforms are intensifying which has led to an improvement in the people's living standards, China's textile and apparel domestic market has also undergone great changes, this paper from 1985 to 2013 has collected data related to China towns and rural residents textile and apparel consumption, analyzing the differences between the two from the aspects of quantity, structure and change, to further explore and analyze the relevant recommendations to enhance the residents of textile and apparel consumption level.
\end{abstract}

\section{Introduction}

Clothing consumption quantity and quality has been greatly improved, especially in terms of quantity, the 1978 national garment production has reached 6.73 billion pieces, per capita 0.7 pieces. In 2005, the number of garment production reached 1.667 billion pieces, per capita around 12.8, by 2014 China's garment production has reached 299.21 billion pieces, per capita 22.5 pieces. However, longstanding urban-rural dual structure will inevitably lead to urban and rural residents in the textile and apparel consumption having significant differences, this difference is bound to affect the structure of China's clothing industry. Therefore, this analysis of differences of urban and rural residents textile and apparel consumption is not only to understand the consumption status and characteristics of residents in our country, but also has positive significance as a reference source for the textile and clothing important role on China's textile industry transformation, upgrades and structural adjustment.

\section{The Nations Residents' Clothing Consumption}

In the early 90s of last century, Professor Tan Ying presided over the original textile industry research "of China's domestic textile market and national consumer textiles development trend and countermeasure" shows that from the beginning of the eighties in the last century, urban residents consumer level for textiles and garments began atransition from subsistence to being well off. In the past 30 years, the urban residents consumption level of textile and clothing has further improve.

From table 1 we can see that in the years 1985-2013, urban residents clothing consumption level has greatly improved, compared with 1985, in 2013 urban residents per capita clothing expenditure increased by about 6.87 times, with an average annual growth of $7.64 \%$ based on the general exponential growth model. The proportion of average per capita clothing expenditure of urban residents has shown an overall downward trend, reduced by about 4 percentage points. 
Table 1 Per capita clothing expenditure from 1985-2013

\begin{tabular}{|c|c|c|c|c|c|}
\hline \multirow[b]{2}{*}{ Year } & \multicolumn{2}{|c|}{ Urban residents } & \multicolumn{2}{|c|}{ rural residents } & \multirow{2}{*}{\begin{tabular}{|l} 
ratio of urban \\
and rural \\
residents
\end{tabular}} \\
\hline & $\begin{array}{l}\text { Per capita clothing } \\
\text { Expenditur(YUAN) }\end{array}$ & $\begin{array}{l}\text { Growth } \\
\text { rate(\%) }\end{array}$ & $\begin{array}{l}\text { Per capita clothing } \\
\text { Expenditur(YUAN) }\end{array}$ & $\begin{array}{l}\text { Growth } \\
\text { rate(\%) }\end{array}$ & \\
\hline 1985 & 98.04 & - & 31.34 & - & 3.13 \\
\hline 1986 & 108.78 & 10.95 & 32.82 & 4.73 & 3.31 \\
\hline 1987 & 111.23 & 2.25 & 32.42 & -1.23 & 3.43 \\
\hline 1988 & 123.02 & 10.61 & 34.90 & 7.65 & 3.52 \\
\hline 1989 & 100.96 & -17.94 & 31.93 & -8.51 & 3.16 \\
\hline 1990 & 108.21 & 7.18 & 30.51 & -4.44 & 3.55 \\
\hline 1991 & 120.96 & 11.78 & 32.98 & 8.06 & 3.67 \\
\hline 1992 & 140.09 & 15.81 & 39.78 & 20.63 & 3.52 \\
\hline 1993 & 160.13 & 14.31 & 40.37 & 1.49 & 3.97 \\
\hline 1994 & 174.16 & 8.76 & 37.64 & -6.78 & 4.63 \\
\hline 1995 & 186.22 & 6.93 & 42.12 & 11.91 & 4.42 \\
\hline 1996 & 190.50 & 2.30 & 49.78 & 18.20 & 3.83 \\
\hline 1997 & 182.13 & -4.39 & 46.57 & -6.45 & 3.91 \\
\hline 1998 & 169.65 & -6.85 & 42.03 & -9.74 & 4.04 \\
\hline 1999 & 174.91 & 3.10 & 40.55 & -3.53 & 4.31 \\
\hline 2000 & 182.38 & 4.27 & 42.87 & 5.73 & 4.25 \\
\hline 2001 & 198.85 & 9.03 & 44.58 & 3.99 & 4.46 \\
\hline 2002 & 226.29 & 13.79 & 48.21 & 8.13 & 4.69 \\
\hline 2003 & 250.75 & 10.81 & 51.34 & 6.51 & 4.88 \\
\hline 2004 & 274.15 & 9.33 & 56.86 & 10.74 & 4.82 \\
\hline 2005 & 326.07 & 18.94 & 70.94 & 24.77 & 4.60 \\
\hline 2006 & 369.53 & 13.33 & 80.56 & 13.56 & 4.59 \\
\hline 2007 & 430.87 & 16.60 & 92.56 & 14.89 & 4.66 \\
\hline 2008 & 490.94 & 13.94 & 101.95 & 10.15 & 4.82 \\
\hline 2009 & 552.92 & 12.62 & 113.73 & 11.56 & 4.86 \\
\hline 2010 & 628.78 & 13.72 & 129.93 & 14.25 & 4.84 \\
\hline 2011 & 713.37 & 13.45 & 164.85 & 26.87 & 4.33 \\
\hline 2012 & 755.56 & 5.91 & 185.14 & 12.31 & 4.08 \\
\hline 2013 & 771.17 & 2.07 & 199.72 & 7.87 & 3.86 \\
\hline
\end{tabular}

Source: "China Statistical Yearbook" for relevant years.

From the table 1, shows that from 1985-2013, the National People's clothing consumption level has been greatly improved, showing a trend of rising close to the index form. Compared with 1985, in 2013 the national average per capita clothing-spending rose 8.61 times, with an average annual growth of $8.42 \%$.

\section{The Differences in Clothing Consumption of Urban and Rural Residents}

Through the above chart, it can be found that there are differences between urban and rural residents in the consumption of textile and clothing, mainly in the following aspects:

The level of clothing consumption of urban residents is much higher than that of rural residents. (see Figure 1) Calculated at comparable prices, in 1985, the per capita expenditure of urban and rural residents was 98.04 Yuan and 31.34 Yuanrespectively; in 2013 it was 771.17 Yuan and 199.72 Yuan. And during this period in each year, the per capita expenditure on clothing of urban residents was 
significantly higher than that of rural residents; the two had 2-4 times differences.

The growth rate of clothing consumption of urban residents is faster than that of rural residents. (see Figure 2) Compared with 1985, 2013 urban residents per capita clothing expenditure increased by 6.87 times, with an average annual growth of $7.64 \%$, while rural residents per capita clothing expenditure increased by 5.37 times, with an average annual growth rate of $6.84 \%$. Leading to the conclusion that urban residents clothing consumption level is rising fasterthan that of the rural residents.

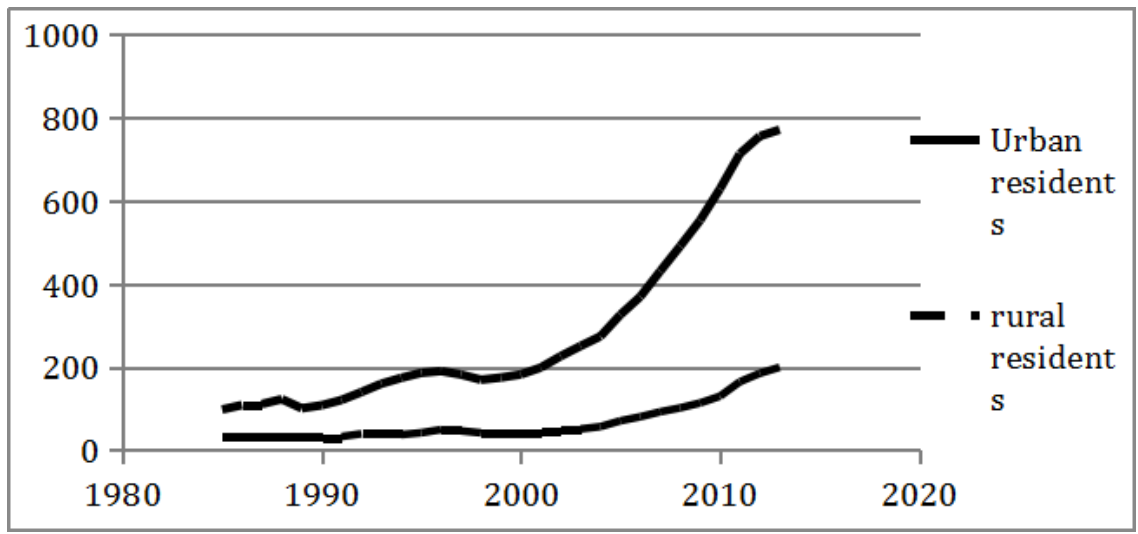

Figure 1 Clothing consumption

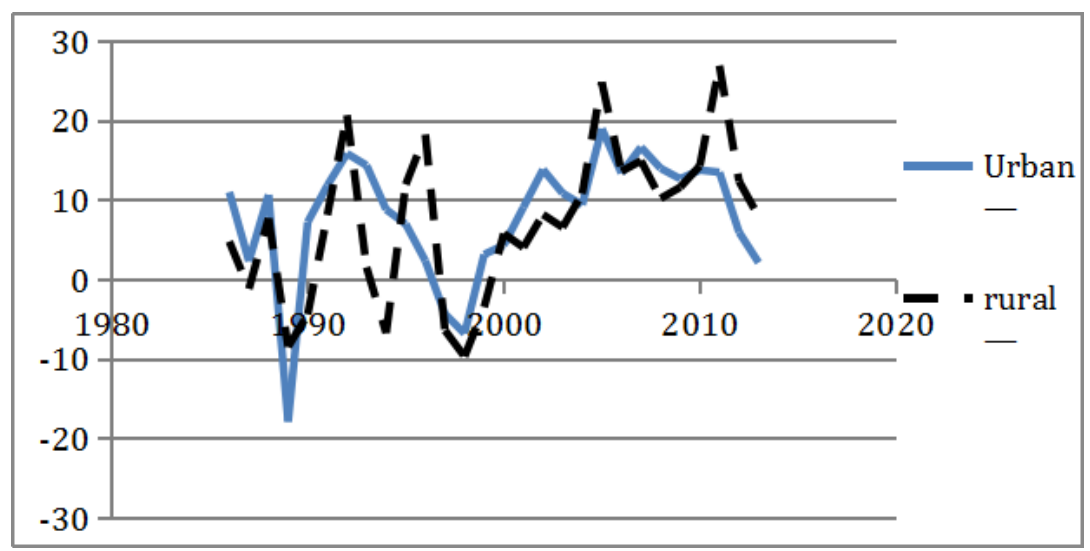

Figure 2 Per capita clothing expenditure growth

The gap between urban and rural residents textile and clothing consumption level. As seen from table 1, the per capita clothing expenditure ratio of urban and rural residents is between 3.13-4.88, the gap between the two before 2003 showed an increasing trend year by year, reaching the maximum in 2003. Since then, the ratio has fluctuated and declined, but it is still as high as 4, see figure 3.

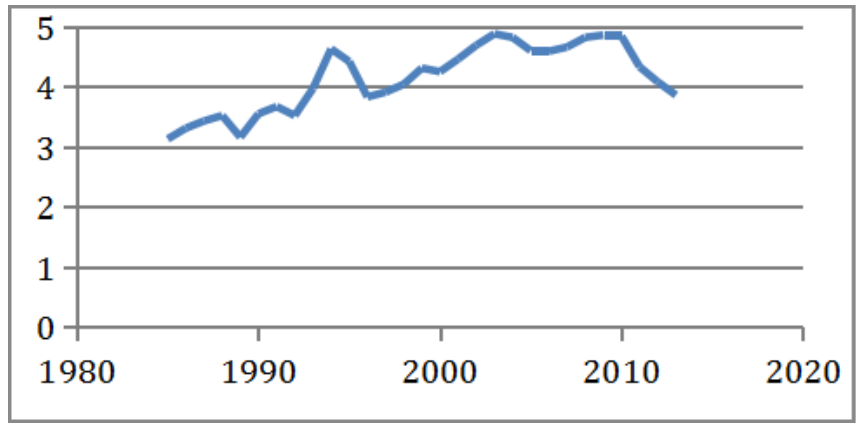

Figure 3 Per capita clothing expenditure ratio 
The importance of clothing consumption for urban and rural residents is very different. In Table 1 it can be found that the urban and rural residents clothing expenditures accounted for the total consumption out of the total proportion, the urban residents per capita expenditure on clothing accounted for is far higher than that of rural residents, urban residents consumption of textiles and garments in their daily life importance is stronger. The reason is mainly because rural residents production and living environment and conditions has restrictions, less social activities, a relatively narrow range of social contacts and the awareness of the concept that determines the textile and apparel consumption demand stays in a low status and low level.

The main body of China's clothing consumption is urban residents. In order to explain the problem, the author calculated the 1985-2013 urban residents and rural residents in their respective clothing expenses accounting for the proportion of total clothing expenditure, see Table 2 which shows the calculation method of the proportion. This fully shows that urban residents are the main body of China's textile and clothing consumption, although in 2011, the population of urban residents is less than that of the rural areas. From the point of view of the relationship between this data this is because urban residents textile and apparel consumption level has always been higher than that of rural residents, on the other hand it is because, the proportion of the population of urban residents continues to increase, until it exceeded the rural population in 2011, its obvious that the urban residents have under significant changes and the differences are apparent, see Table 2:

Table 2 Clothing expenditure accounted for the total consumption expenditure proportion

\begin{tabular}{|c|c|c|}
\hline Year & Urban residents(\%) & rural residents(\%) \\
\hline 1985 & 14.56 & 9.87 \\
\hline 1986 & 14.15 & 9.45 \\
\hline 1987 & 13.69 & 8.59 \\
\hline 1988 & 13.88 & 8.64 \\
\hline 1989 & 12.32 & 8.29 \\
\hline 1990 & 13.36 & 7.77 \\
\hline 1991 & 13.73 & 8.23 \\
\hline 1992 & 14.39 & 9.50 \\
\hline 1993 & 14.24 & 8.56 \\
\hline 1994 & 13.69 & 6.92 \\
\hline 1995 & 13.55 & 6.85 \\
\hline 1996 & 13.47 & 7.24 \\
\hline 1997 & 12.45 & 6.77 \\
\hline 1998 & 11.10 & 6.17 \\
\hline 1999 & 10.45 & 5.83 \\
\hline 2000 & 10.01 & 5.75 \\
\hline 2001 & 10.05 & 5.67 \\
\hline 2002 & 9.80 & 5.72 \\
\hline 2003 & 9.79 & 5.67 \\
\hline 2004 & 9.56 & 5.50 \\
\hline 2005 & 10.08 & 5.81 \\
\hline 2006 & 10.37 & 5.94 \\
\hline 2007 & 10.42 & 6.00 \\
\hline 2008 & 10.37 & 5.79 \\
\hline 2009 & 10.47 & 5.82 \\
\hline 2010 & 10.72 & 6.03 \\
\hline 2011 & 11.05 & 6.54 \\
\hline
\end{tabular}




\begin{tabular}{|l|l|l|}
\hline 2012 & 10.94 & 6.71 \\
\hline 2013 & 10.55 & 6.62 \\
\hline
\end{tabular}

Source: "China Statistical Yearbook" for relevant years.

The main reason to Analyze the above differences, on the one hand depends on the number of people, on the other hand to look at differences in clothing needs. First of all, in 2011, China's urban population has exceeded the rural population, in 2013, the number of urban population reached 730 million accounting for $53.73 \%$ of the total population of the country. Relevant information also shows that urban residents in China from the beginning of the eighties of the last century have began to change from subsistence living level to transition into a well-off level, urban residents textile and apparel consumption level have improved significantly, so that China's urban residents in the clothing consumption index occupies a important position. In addition, with the acceleration of urbanization, the number of cities and towns in our country has been increasing, the size of the towns has also been gradually expanding, and the number of urban population has been increasing. Furthermore, the rapid development of China's economy has promoted the improvement of the income level of residents, promoting the increase in the number of demand of residents for textile and clothing, but also led to changes in the consumer psychology about clothing consumption. That residents in textile and clothing consumption demand is no longer based on just keeping warm or the basic needs of life, but gradually changing to more aesthetic needs.

\section{Conclusions}

Raise the income level of residents, enhance the level of the consumption of textile and clothing. The government should take a number of measures to increase the employment channels, increase employment opportunities, stabilize and improve the basic operating system, broaden the income of residents, thereby improving the overall income level of residents.

The important factor that determines the overall level of China's textile and apparel consumption is the consumption level of urban residents and rural residents as well as the number of the general population. The government should vigorously carry out employment training in rural areas, improve the employment ability of farmers, improve the employment status of farmers, to achieve the increase of farmers income, and thus promote the clothing consumption.

To promote the process of urbanization, and promote the consumption of textile and clothing

The government should accelerate the process of urbanization in rural areas. The government should strengthen the construction of infrastructure in rural areas, vigorously improve the mode of production and life of rural residents, the development of electronic commerce, rich textile and apparel consumption channels to improve and enhance the consumer market environment, taking effective forms of propaganda to update the rural residents consumer concept for textiles and garments, and stimulate the consumption demand of rural residents in textiles and clothing.

Adjust the industrial structure, so that it is in accord with the needs of residents. Textile industry at all levels of various associations and organizations should always comprehend theconsumption status of the residents of China's textile and apparel, note the differences and changes of trends, to be consumption demand oriented, allowing for rational allocation of industry resources, improving industrial structure, stabilizing supply of raw materials, optimizing raw material structures, the integration of industrial chain, to improve the capability of the product design- adjusting industrial layout, and to promote domestic and foreign industrial system coordination and cohesion, enhancing the sense of market marketing, to expand the supply of clothing to ensure the quantity and quality of textiles and garments consumed by residents.

To strengthen the guidance, to stimulate the residents of clothing consumption. Consumer economics points out that the residents' consumption needs correct guidance. Therefore, relevant government agencies and industry organizations should increase investment, to take effective measures, 
through a variety of ways, to carry out rich and effective promotional activities to enable more residents to understand the knowledge of textiles and garments, to understand the development of new products, to guide residents in the textile and apparel consumption setting up correct consumption views, stimulating the residents to areasonably healthy consumption of textiles and garments.

\section{Acknowledgements}

The paper is the stage results of the project which number is "TJJX13-019" in 2014

\section{References}

[1] Wei Yuan, Statistics , BeiJing: High Education publisher, Vol. 6(2014) p.121-123

[2] Zhang Xiaotong, Eviews Use guide and case, BeiJing: Machinery Industry Publisher, Vol. 1(2007) p.215-223

[3] Gao Tiemei, Econometric analysis method and model establishment : Eviews application and example, BeiJing: Qinghua University Publisher, Vol. 1(2009) p.115-128

[4] Roman Rosipal,Milos Koska,Igor Farkas.Prediction of chaotic time series with aresourceallocating RBF network,Neural processing letters, Vol. 4(1998) p. 185-197

[5] A.L. Espareia-Alcazar,K.C.Sharman.genetic programming techniques that evolve recurrent neural network architectures for signal processing, Proceedings of the IEEE Workshop, Neural Networks for Signal Processing, Vol. 3(1996) p. 139-148 